\title{
Gel immersion endoscopy simplifies hemostasis during endoscopic submucosal dissection using the pocket-creation method
}

Gel immersion endoscopy (GIE) is a novel method to secure the visual field using gel with an appropriate viscosity, even during ongoing bleeding [1], and is effective in the narrow lumen of the gastrointestinal tract. Recently, GIE was reported to be useful for unexpected arterial bleeding during endoscopic submucosal dissection (ESD) [2]. However, the gel may be difficult to apply in the large lumen of the stomach. The pocket-creation method (PCM) is a new ESD strategy, which is characterized by entering the submucosal layer with a minimal mucosal incision and dissecting the submucosal layer completely under the lesion before the circumferential mucosal incision, as if a "pocket" is made [3]. In this narrow "pocket," GIE can be applied easily, even when there is massive arterial bleeding where water infusion alone cannot secure the endoscopic view ( $\triangleright$ Fig. 1, $\triangleright$ Fig. 2).

A 78-year-old man was referred for endoscopic resection of a flat elevated 50-mm gastric tumor on the lesser curvature of the antrum. We performed ESD using PCM with a therapeutic-type endoscope (EG-L580RD; Fujifilm, Tokyo, Japan) and a small-caliber-tip transparent hood (DH15-GR; Fujifilm) ( Video 1). After incision of the mucosa on the proximal side of the tumor, the submucosal layer was dissected to make a pocket. However, a large vessel was injured accidentally during this procedure. We tried to achieve hemostasis with forceps, but the bleeding point could not be visualized because of a rapid collection of blood. Continuous water injection enabled transient visualization, but water and blood mixed immediately, leading to insufficient visualization. After continuous injection of gel (OS-1 JELLY; Otsuka Pharmaceutical Factory, Tokushima, Japan), we could identify the bleeding point. After the bleeding point has been

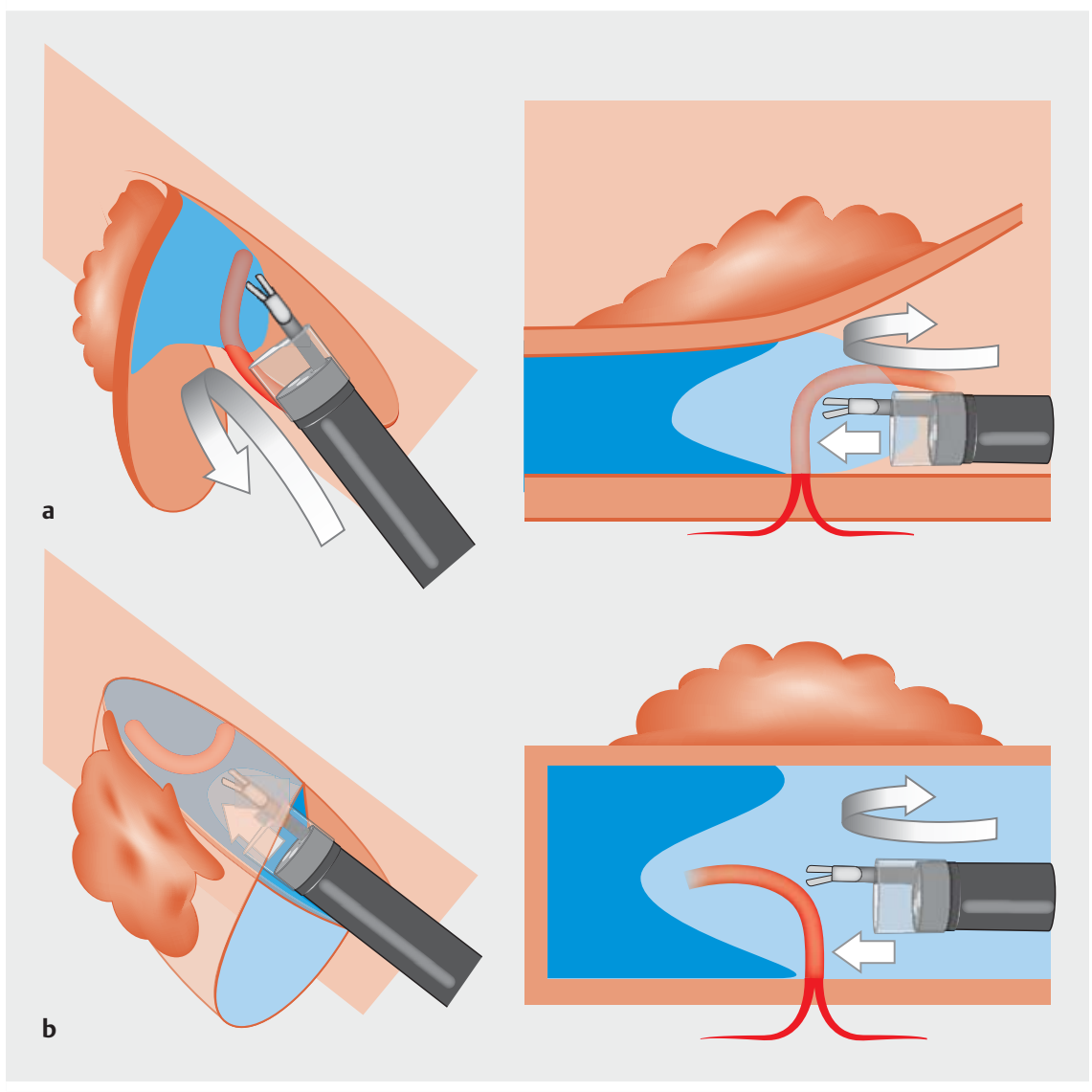

- Fig. 1 Advantages of gel immersion endoscopy during endoscopic submucosal dissection using the pocket-creation method (PCM) compared with conventional endoscopic submucosal dissection (ESD). a In conventional ESD with a large mucosal incision, it is difficult to maintain a collection of gel because of the large space. $\mathbf{b}$ In ESD using PCM, it is easy to maintain the collection of gel because the cavity is small; moving the blood forward allows good visualization, enabling the bleeding point to be identified and managed by hemostatic forceps.

grasped with forceps, the gel should be replaced with gas before applying electrocoagulation. Using this method, we achieved hemostasis.

GIE simplifies hemostasis during ESD with PCM and can be a standard strategy throughout the gastrointestinal tract.

Endoscopy_UCTN_Code_CPL_1AH_2AC
Competing interests

Hironori Yamamoto has patents for ESD devices and double-balloon endoscopy produced by Fujifilm Corporation, and have received royalties from the company. Hironori Yamamoto and Hiroyuki Osawa are consultants for Fujifilm Corporation and have received honoraria and grants from the company. Yoshimasa Miura and Tomonori Yano have received honoraria from Fujifilm Corporation. 


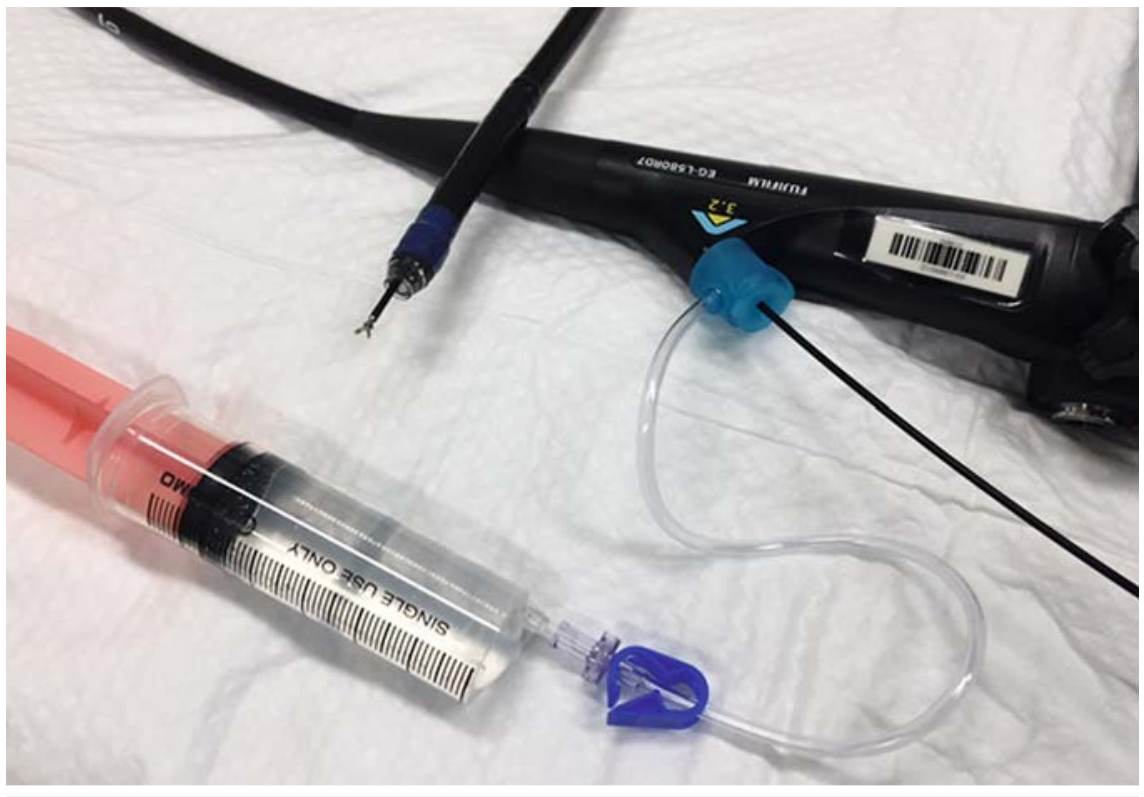

- Fig. 2 Gel immersion endoscopy equipment. It is important to inject the gel (OS-1 JELLY; Otsuka Pharmaceutical Factory, Tokushima, Japan) continuously with hemostatic forceps inserted through the accessory channel. The BioShield-irrigator (US Endoscopy, Mentor, Ohio, USA) is necessary to perform gel immersion endoscopy.
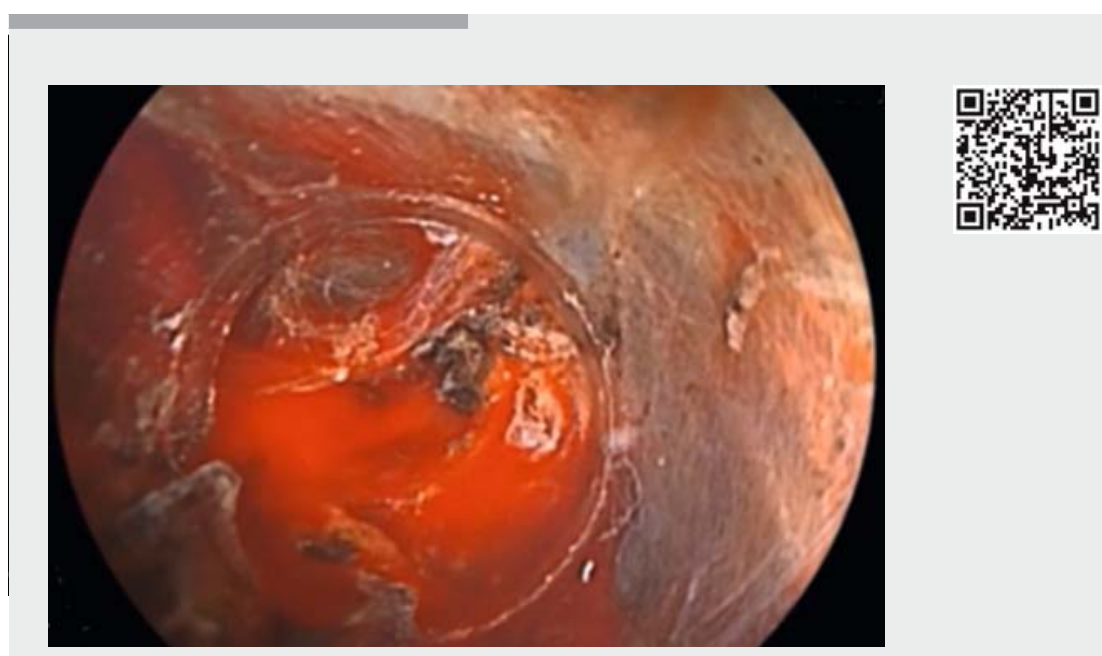

Video 1 The combination of gel immersion endoscopy and the pocket-creation method facilitates hemostasis during endoscopic submucosal dissection.

The authors

Yoshimasa Miura', Tomonori Yano' ${ }^{1}$, Takahito Takezawa' ${ }^{1}$, Hirotsugu Sakamoto ${ }^{1}$, Hiroyuki Osawa ${ }^{1}$, Alan K Lefor ${ }^{2}$, Hironori Yamamoto ${ }^{1}$

1 Department of Medicine, Division of Gastroenterology, Jichi Medical University, Shimotsuke, Japan

2 Department of Surgery, Jichi Medical University, Shimotsuke, Japan

\section{References}

[1] Yano T, Nemoto D, Ono K et al. Gel immersion endoscopy: a novel method to secure the visual field during endoscopy in bleeding patients (with videos). Gastrointest Endosc 2016; 83: 809-811

[2] Akasaka T, Takeuchi Y, Ishida $\mathrm{H}$ et al. A novel gel immersion technique using a bipolar needle-knife in endoscopic submucosal dissection for superficial gastrointestinal neoplasms. Ann Gastroenterol 2018; 31: 247

[3] Hayashi Y, Sunada K, Takahashi H et al. Pocket-creation method of endoscopic submucosal dissection to achieve en bloc resection of giant colorectal subpedunculated neoplastic lesions. Endoscopy 2014; 46 (Suppl. 01): E421-E422

\section{Bibliography}

DOI https://doi.org/10.1055/a-0651-0365

Published online: 8.8.2018

Endoscopy 2018; 50: E294-E295

(c) Georg Thieme Verlag KG

Stuttgart · New York

ISSN 0013-726X

\section{ENDOSCOPY E-VIDEOS \\ https://eref.thieme.de/e-videos}

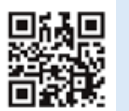

Endoscopy E-Videos is a free access online section, reporting on interesting cases and new techniques in gastroenterological endoscopy. All papers include a high quality video and all contributions are freely accessible online.

This section has its own submission website at

https://mc.manuscriptcentral.com/e-videos

\section{Corresponding author}

\section{Hironori Yamamoto, MD, PhD}

3311-1 Yakushiji, Shimotsuke, Tochigi

329-0498, Japan

Fax: +81-285-406598

ireef@jichi.ac.jp 